\title{
BIOADSORBEN SALINITAS SEDERHANA BERBASIS LIMBAH LINGKUNGAN
}

\section{SIMPLE BIOADSORBENT TOWARD SALINITY BASED ON ENVIRONMENTAL WASTE}

\author{
Eka Junaidi*, Jeckson Siahaan, dan Aliefman Hakim \\ Program Studi Pendidikan Kimia FKIP Universitas Mataram, Mataram, Indonesia. \\ Email: xjuned@yahoo.com
}

Diterima: 13 Januari 2020. Disetujui: 20 Januari. Dipublikasikan: 2 Maret 2020

\begin{abstract}
Abstrak: Penelitian ini bertujuan untuk memberikan informasi serta rekomendasi ilmiah upaya mengurangi kadar $\mathrm{NaCl}$ pada air laut yang berpotensi menjadi air layak minum secara sederhana, berbiaya murah dengan memanfaatkan limbah sekitar tempat tinggal (Batang Pisang, Enceng Gondok dan Abu Gosok). Penelitian ini merupakan penelitian eksperimen laboratorium. Untuk menentukan kadar $\mathrm{NaCl}$ sebelum dan sesudah dilewatkan adsorben dapat dilakukan menggunakan teknik analisa argentometri. Teknik analisa argentometri tergolong mudah dilakukan, tidak membutuhkan waktu yang lama dengan tingkat akurasi yang cukup tinggi. Penelitian ini menggunakan material limbah sebagai adsorben dengan berat total sebanyak 20 gram dengan berbagai variasi komposisi. Konsentrasi $\mathrm{NaCl}$ yang digunakan sebagai larutan yang dilewatkan sebesar $0,1 \mathrm{M}$, bervolume $150 \mathrm{~mL}$ dengan waktu perendaman sekitar 10 menit. Setelah perendaman selesai, larutan $\mathrm{NaCl}$ diambil sebanyak $20 \mathrm{~mL}$, dilanjutkan dengan proses titrasi dengan dua kali pengulangan untuk dianalisis konsentrasi $\mathrm{NaCl}$ yang tertinggal pada adsorben. Berdasarkan hasil ekperimen diperoleh komposisi adsorben paling optimal mengurangi kadar $\mathrm{NaCl}$ adalah Batang Pisang 5 gram, Enceng Gondok 5 gram dan Abu Gosok 10 gram. Pada komposisi tersebut kemampuan adsorben mengadsorpsi $\mathrm{NaCl}$ rata - rata sebesar $0,08525 \mathrm{M}$ atau $\mathrm{NaCl}$ yang teradsorpsi sebesar $85,25 \%$. Sedangkan untuk uji coba menggunakan sampel air laut (Pantai Gading Lombok) digunakan komposisi adsorben paling optimal mengurangi kadar $\mathrm{NaCl}$ dan diperoleh kemampuan adsorben mengadsorpsi sebesar 56,36\%.
\end{abstract}

Kata Kunci: Batang Pisang, Enceng Gondok, Abu Sekam, Adsorben, Limbah, Argentometri, Salinitas

\begin{abstract}
The goals of this research are to provide scientific information and recommendation in reducing concentration of $\mathrm{NaCl}$ in sea water, so the water itself can be used as household daily needs and drinking water in a simple way such low budget by using of banana trunks, enceng gondok, and ash straw wastes from surrounding. This work is a laboratory experimental research. To determine the content of $\mathrm{NaCl}$ in sea water before and after passes through the adsorbent, it can be conducted by applying of argentometry analisis method. This method is easy to be conducted, just need short time period with high enough degree of accuration. This research used $20 \mathrm{gr}$ of mixing of waste materials as adsorbent in various composition. A $150 \mathrm{~mL} \mathrm{of} \mathrm{NaCl}$ solution $0.1 \mathrm{M}$ is passed through adsorbent in 10 minutes soaking time.After soaking time, a $20 \mathrm{~mL} \mathrm{of} \mathrm{NaCl}$ solution is taken and then is titrated in order to analise the concentration of $\mathrm{NaCl}$ that is stayed in adsorbent. This titration is conducted in two replicates. Based on the results of experiment, the optimal reduction of $\mathrm{NaCl}$ content is found in composition of adsorbent such as banana trunks $5 \mathrm{gr}$, enceng gondok $5 \mathrm{gr}$, and ash straw10 gr. In such composition, the capability of adsobent to adsorb $\mathrm{NaCl}$ in average is $0.08525 \mathrm{M}$ or $\mathrm{NaCl}$ adsorbed as $85.25 \%$. At the meanwhile, for test driven by using sea water sample from Gading Beach, Lombok, Indonesia by applying the optimal composition of adsorbent to reduce $\mathrm{NaCl}$ content and it is found that the capability of adsorbent to adsorb is $56.36 \%$.
\end{abstract}

Key words: Banana trunks, enceng gondok, ash straw, adsorbent, wastes, argentometry, salinity

\section{PENDAHULUAN}

Air merupakan kebutuhan mendasar bagi tubuh. Sekitar 50-70\% tubuh manusia tersusun atas air. Ketika cairan yang ada dalam tubuh berkurang (terjadi dehidrasi), maka upaya tubuh menyeimbangkan kadar air dalam tubuh dengan cara mengambil sumber air lain yang ada dalam komponen tubuh sendiri, akibatnya kinerja organ tubuh yang lain juga akan terganggu. Meskipun wilayah bumi Indonesia tiga perempat dari permukaannya ditutupi dengan air kenyataannya 98\% air tersebut adalah air asin dan hanya sekitar $1 \%$ saja permukaan air di bumi yang bisa dinikmati oleh warganya. Salah satu daerah yang paling rentan dengan ketersediaan air minum adalah daerah pesisir [1]. Kerentanan pemenuhan air minum tersebut bisa disebabkan oleh kondisi geografis wilayahnya sehingga susah dijangkau atau karena air yang ada di sekeliling wilayah tersebut merupakan air asin yang tidak bisa langsung diminum. Oleh karena itu 
sebagai salah satu upaya mengatasi pemenuhan kebutuhan air minum daerah pesisir bagi masyarakat dengan penghasilan rendah adalah penggunaan teknologi pengolahan air yang berbiaya murah, cara pengolahan sederhana serta memanfaatkan material pengolahan (adsorben) yang murah (dapat ditemukan di daerah sekitar tempat tinggal atau memanfaatkan limbah sekitar tempat tinggal), misalnya pemanfaatan limbah batang pisang, enceng gondok dan abu gosok [30].

Batang pisang adalah limbah yang banyak dijumpai di daerah sekitar rumah tempat tinggal. Pada tahun 2016, jumlah produksi pisang di wilayah Nusa Tenggara Barat mencapai 75.509 Ton [2]. Sehabis pisang dipanen, umumnya batang pisang akan menjadi limbah karena tidak banyak masyarakat yang memanfaatkan (kalaupun ada yang memanfaatkan hanya untuk keperluan kecil misalnya sebagai bahan makanan ternak, atau untuk dikonsumsi misalnya di daerah lombok, batang pisang dijadikan bahan makanan ares). Secara umum komposisi kimia batang pisang terdiri atas holoselulosa $60,1-65,2 \%$, selulosa $34,5-40,2 \%$ dan lignin $12-12,7 \%$ [3], komposisi kimia batang pisang terdiri atas holoselulosa $72,7 \%$, selulosa $39,12 \%$ dan lignin $8,88 \%$ [4]. Sedangkan kemampuan batang pisang sebagai adsorben telah banyak dilaporkan terutama untuk adsorpsi logam berat diantaranya logam $\mathrm{Cu}$ [5], ion $\mathrm{Cr}^{+6}$ [6], [7], Logam $\mathrm{Fe}$ [8], selain itu batang pisang juga dapat dimanfaatkan untuk menurunkan tingkat kesadahan air dan fosfat [9][10].

Demikian pula dengan enceng gondok. Tumbuhan ini memiliki kecepatan tumbuh yang tinggi sehingga sering dianggap sebagai gulma yang dapat merusak lingkungan perairan. Secara umum komposisi kimianya terdiri atas hemiselulosa $35 \%$, selulosa $25 \%$, lignin $10 \%$, ash $20 \%$ dan Nitrogen $3 \%$ [11][12]. Untuk kemampuannya sebagai adsorben, enceng gondok telah banyak dilaporkan diantaranya sebagai oil adsorbant, fosfor, logam Cd [13][14][15]. Methylene blue, ion $\mathrm{Cu}^{2+}$ dan ion $\mathrm{Zn}^{2+}$, logam $\mathrm{Pb}$, logam $\mathrm{Fe}$, adsorpsi warna minyak sawit mentah, penyerap warna pada limbah industri tekstil, fenol [16][17][18][19][20][10][15][21].

Material lain yang sering juga dijumpai adalah abu gosok. Abu gosok merupakan salah satu limbah pembakaran atau abu dari tumbuhan yang biasanya berasal dari sekam padi, sisa pembakaran industri batu bata dan sebagainya. Abu gosok memiliki komposisi kimia $\mathrm{SiO}_{2} 53,09 \%, \quad \mathrm{Al}_{2} \mathrm{O}_{3}$ $24,80 \%, \mathrm{Fe}_{2} \mathrm{O}_{3} 8,01 \%$ [22]. Kemampuan abu gosok sebagai adsorben telah banyak diteliti, misalnya penurunan kadar congo red [23], penghilangan $\mathrm{HCN}$ pada umbi Gadung [24], ion $\mathrm{Cr}^{+6}$ [25], penyerap ion $\mathrm{Cd}$ dan ion $\mathrm{Cr}$ [26], penurunan zat warna limbah cair industri, logam $\mathrm{Pb}$ [27][28].

Berdasarkan informasi hasil eksperimen yang diungkapkan di atas, peluang pemanfaatan limbah sebagai adsorben sangat besar berdasarkan kemampuan adsorpsi material yang dimaksud, meskipun pelaporan tentang Pemanfaatan Limbah Batang Pisang, Enceng Gondok dan Abu Gosok secara simultan Sebagai Adsorben Salinitas Sederhana masih belum banyak dilaporkan. Dengan demikian peluang untuk mengupayakan pemenuhan kebutuhan air minum dari bahan baku air laut menggunakan adsorben limbah (batang pisang, enceng gondok dan abu gosok) akan sangat memungkinkan untuk dilakukan, dengan metode pengolahan yang sederhana dan berbiaya murah.

\section{METODE PENELITIAN \\ Preparasi Adsorben}

Batang Pisang dan Enceng Gondok yang sudah dibersihkan diangin-anginkan hingga kering, kemudian dihaluskan secara terpisah hingga ukuran partikelnya merata. Kemudian semua bahan material adsorben ditimbang sesuai dengan komposisi yang diinginkan dan digabungkan dengan total adsorben yang akan dipakai sebanyak 20 gram.

\section{Proses Perendaman}

Pada tahap ini Adsorben direndam dalam wadah kolom dengan waktu perendaman selama 10 menit menggunakan larutan standar $\mathrm{NaCl} 0,1 \mathrm{M}$ sebanyak $150 \mathrm{~mL}$ (larutan $\mathrm{NaCl}$ terlebih dahulu distandarisasi menggunakan Larutan $\mathrm{AgNO}_{3}$ ). Setelah perendaman selesai kemudian air rendaman diambil sebanyak 20 $\mathrm{mL}$ untuk dilakukan titrasi menggunakan larutan $\mathrm{AgNO}_{3}$. Titrasi dilakukan sebanyak 2 kali untuk mendapatkan hasil rata-rata.

\section{Penentuan Kadar $\mathrm{NaCl}$ yang Tertinggal pada Adsorben}

Dengan metode titrasi Argentometri dapat diketahui konsentrasi $\mathrm{NaCl}$ yang tertahan di adsorben melalui pengurangan konsentrasi $\mathrm{NaCl}$ yang dipergunakan sebelum dilewatkan adsorben terhadap konsentrasi $\mathrm{NaCl}$ setelah dilewatkan adsorben. Hasil pengurangan tersebut dianggap sebagai jumlah konsentrasi $\mathrm{NaCl}$ yang tertinggal pada adsorben. Sedangkan untuk sampel air laut, penentuan kadar $\mathrm{NaCl}$ yang tertahan digunakan komposisi adsorben paling optimal yang mampu mengurangi $\mathrm{NaCl}$ dari jumlah sebelum dilewatkan adsorben.

\section{HASIL DAN PEMBAHASAN}

Berdasarkan hasil eksperimen laboratorium diperoleh bahwa kadar $\mathrm{NaCl}$ paling tinggi tertahan menggunakan adsorben Abu Gosok (untuk penggunaan satu jenis adsorben) dengan kadar $\mathrm{NaCl}$ yang tertahan sebesar $0,8375 \mathrm{M}$ atau $83,75 \%$. Berdasarkan data hasil eksperimen yang ditunjukkan pada tabel.1 tersebut sekaligus juga membuktikan 
bahwa kemampuan Abu Gosok (abu sekam) sangat efektif digunakan sebagai adsorben untuk logamlogam berat, penyerapan logam $\mathrm{Pb}$ oleh abu gosok yang diaktifasi menggunakan $\mathrm{HCl}$, dapat mencapai 99\% dengan ukuran adsorben 80 mesh [28].

Sedangkan pada tabel.2 dan tabel.3 dapat ditunjukkan bahwa penggunaan gabungan dua jenis adsorben diperoleh informasi kadar $\mathrm{NaCl}$ yang tertahan paling tinggi menggunakan gabungan $\mathrm{Abu}$ Gosok (10 gram) dan Enceng gondok (10 gram) dengan kadar $\mathrm{NaCl}$ yang tertahan sebesar $0,80 \mathrm{M}$ atau sebesar $80 \%$. Sedangkan jika menggunakan gabungan tiga jenis adsorben, kadar $\mathrm{NaCl}$ paling tinggi tertahan menggunakan adsorben dengan komposisi 10 gram Abu Gosok, 5 gram Batang Pisang dan 5 gram Enceng Gondok dengan kemampuan menahan kadar $\mathrm{NaCl}$ sebesar $0,8525 \mathrm{M}$ atau sebesar $85,25 \%$.

Fakta ini juga sekaligus menunjukkan bahwa ketiga adsorben tersebut memiliki kemampuan yang baik dalam menahan kadar $\mathrm{NaCl}$. Komposisi ini yang kemudian disimpulkan sebagai komposisi adsorben paling optimal yang mampu menahan $\mathrm{NaCl}$ paling tinggi. Sesudah dilakukan optimasi komposisi adsorben yang paling baik menahan $\mathrm{NaCl}$, kemudian dilakukan pengujian sampel air laut (Pantai Gading Lombok) dengan komposisi adsorben paling optimal dan diperoleh bahwa kemampuan gabungan adsorben tersebut menahan $\mathrm{NaCl}$ sebesar $56,36 \%$. (tabel.4)

Penelitian ini menggunakan bahan limbah berupa Abu Gosok, Batang Pisang dan Enceng Gondok yang banyak dijumpai disekitar lingkungan yang dianggap sebagai limbah. Ketiga material adsorben ini masing-masing dapat berfungsi sebagai penyerap dalam hal ini $\mathrm{NaCl}$. Dugaan ini dikuatkan pula oleh kemampuan batang pisang, enceng gondok maupun abu sekam yang telah dilaporkan beberapa peneliti yang kesemuanya memiliki pendapat bahwa ke tiga adsorben yang digunakan masing-masing memiliki kemampuan yang baik sebagai adsorben. Kemampuan batang pisang sebagai pengadsorpsi $\mathrm{Cu}$ mempunyai kapasitas optimum dan persentase adsorpsinya secara berturut turut adalah $19,7 \mathrm{mg} / \mathrm{g}$ dan 97,0\% [5]. Kapasitas adsorpsi arang batang pisang pada ion $\mathrm{Cr}^{6+}$ sebesar $0,8019 \mathrm{mg} / \mathrm{g}$, yang diperoleh pada waktu setimbang 40 menit dengan konsentrasi awal sebesar 75 ppm [6]. Sedangkan, serat batang pisang dapat digunakan untuk menghilangkan ion $\mathrm{Cr}^{6+}$ sampai $95 \%$ dan $78 \%$ dari dengan waktu kontak sampai 300 menit [7]. Arang batang pisang mampu mengadsorpsi terhadap ion $\mathrm{Cu} 2+$ sebesar $2,8112 \mathrm{mg} / \mathrm{g}$ pada konsentrasi 100 ppm sedangkan untuk ion $\mathrm{Mg} 2+$ mengadsorpsi sebesar 2,3371 $\mathrm{mg} / \mathrm{L}$ pada konsentrasi 75 ppm [9]. Penambahan 15 gram adsorben batang pisang, kadar fosfat dalam limbah mampu dikurangi sebesar 8,91 $\mathrm{mg} / \mathrm{L}$ dari keadaan awal sebesar 10,26 mg/L [10]. Sedangkan untuk enceng gondok, enceng gondok dapat dijadikan sebagai adsorben untuk menurunkan kadar fosfor setelah divariasikan waktu kontaknya dengan limbah kotoran babi [14]. Keberadaan enceng gondok pada larutan uji yang mengandung logam $\mathrm{Cd}$ $0,2 \mathrm{ppm}$ diperairan juga dapat teradsorpsi sangat efektif menggunakan enceng gondok setelah dilakukan kontak selama 6 hari [29]. Enceng gondok sebagai pengadsorpsi pada limbah laundry [10]. Kadar fosfat dalam limbah mampu dikurangi sebesar $8,84 \mathrm{mg} / \mathrm{L}$ dari keadaan awal sebesar 10,26 mg/L.

Selain itu, sekam padi juga telah dilaporkan mampu menyerap ion $\mathrm{Pb}$ dan ion $\mathrm{Cu}$ dalam air limbah. Kemampuan sekam padi pada adsorpsi air limbah yang diuji menggunakan instrumentasi serapan atom, dengan hasil pada limbah yang mengandung ion $\mathrm{Pb}$ terserap hingga 99,38\%, sedangkan ion $\mathrm{Cu}$ terserap hingga 78,57\% [26].

Sedangkan pada tabel.4 diperoleh informasi tentang hasil uji coba komposisi adsorben paling optimal berdasarkan hasil pada tabel.3 (10 gram abu gosok, 5 gram batang pisang dan 5 gram enceng gondok). Berdasarkan data tersebut diatas kemudian dilakukan uji pada sampel air laut yang diambil pada Pantai Gading Lombok. Dengan prosedur yang sama seperti pada perlakuan menggunakan larutan $\mathrm{NaCl}$ $0,1 \mathrm{M}$, sampel air laut dilewatkan pada kolom yang berisi tiga adsorben dengan waktu perendaman 10 menit kemudian diambil sebanyak $20 \mathrm{~mL}$ untuk dititrasi dengan larutan $\mathrm{AgNO}_{3}$ yang sudah distandarisasi. Berdasarkan hasil titrasi tersebut diketahui bahwa kemampuan adsorben mengurangi kadar $\mathrm{NaCl}$ sebesar $56,36 \%$ setelah dilakukan pengulangan dua kali. Hasil tersebut tidak semaksimal hasil pada uji coba menggunakan larutan $\mathrm{NaCl} 0,1 \mathrm{M}$, hal ini diduga terjadi karena pada air laut tidak hanya terdiri atas $\mathrm{NaCl}$ saja tetapi ada juga jenis garam yang lain. Sehingga untuk mengetahui ada atau tidak garam yang lain perlu dilakukan uji dengan metode lain (metode argentometri tidak cukup baik untuk mendeteksi jenis garam selain $\mathrm{NaCl})$.

\section{KESIMPULAN}

Abu gosok menjadi adsorben paling baik untuk mengurangi kadar $\mathrm{NaCl}$ dengan kemampuan sampai 83,75\% (20 gram) jika dibandingkan dengan enceng gondok maupun Batang Pisang. Gabungan abu gosok (10 gram) dan enceng gondok (10 gram) dapat mencapai $80 \%$, sedangkan untuk gabungan tiga adsorben maka komposisi paling baik terdiri atas abu gosok (10 gram), batang pisang (5 gram) dan enceng gondok (5 gram) dengan kemampuan 85,25\%. Komposisi optimal gabungan adsorben yang sudah diperoleh kemudian digunakan untuk menguji kadar $\mathrm{NaCl}$ dalam air laut (Pantai Gading Lombok) dan 
J. Pijar MIPA, Vol. 15 No.2, Maret 2020: 165-170

DOI: $10.29303 / j p m . v 15 i 2.1625$
ISSN 1907-1744 (Cetak)

ISSN 2460-1500 (Online)

diperoleh kemampuan mengurangi kadar $\mathrm{NaCl}$

sebesar $56,36 \%$.

Tabel.1 Konsentrasi $\mathrm{NaCl}$ yang tertahan pada adsorben menggunakan satu (1) jenis adsorben

\begin{tabular}{|c|c|c|c|c|c|c|c|c|}
\hline \multirow[b]{2}{*}{ Perlakuan } & \multicolumn{3}{|c|}{ Komposisi Adsorben (gram) } & \multirow{2}{*}{$\begin{array}{c}\text { Kadar } \\
\text { AgNO3 }\end{array}$} & \multirow{2}{*}{$\begin{array}{l}\text { Volume } \\
\text { AgNO3 }\end{array}$} & \multirow{2}{*}{$\begin{array}{l}\text { Volume } \\
\mathrm{NaCl}\end{array}$} & \multirow{2}{*}{$\begin{array}{l}\text { Kadar } \\
\mathrm{NaCl}\end{array}$} & \multirow{2}{*}{$\begin{array}{l}\% \text { Kadar } \mathrm{NaCl} \\
\text { yang Tertahan }\end{array}$} \\
\hline & $\begin{array}{c}\text { Abu } \\
\text { Gosok }\end{array}$ & $\begin{array}{l}\text { Batang } \\
\text { Pisang }\end{array}$ & $\begin{array}{c}\text { Eceng } \\
\text { Gondok }\end{array}$ & & & & & \\
\hline 1 & 20 & 0 & 0 & 0,1 & 3,25 & 20 & 0,01625 & 83,75 \\
\hline 2 & 0 & 0 & 20 & 0,1 & 5,05 & 20 & 0,02525 & 74,75 \\
\hline 3 & 0 & 20 & 0 & 0,1 & 9,6 & 20 & 0,048 & 52,00 \\
\hline
\end{tabular}

Tabel.2 Kadar $\mathrm{NaCl}$ yang tertahan pada adsorben menggunakan dua (2) jenis adsorben

\begin{tabular}{|c|c|c|c|c|c|c|c|c|}
\hline \multirow[b]{2}{*}{ Perlakuan } & \multicolumn{3}{|c|}{ Komposisi Adsorben (gram) } & \multirow{2}{*}{$\begin{array}{c}\text { Kadar } \\
\text { AgNO3 }\end{array}$} & \multirow{2}{*}{$\begin{array}{l}\text { Volume } \\
\text { AgNO3 }\end{array}$} & \multirow{2}{*}{$\begin{array}{l}\text { Volume } \\
\mathrm{NaCl}\end{array}$} & \multirow{2}{*}{$\begin{array}{l}\text { Kadar } \\
\mathrm{NaCl}\end{array}$} & \multirow{2}{*}{$\begin{array}{l}\% \text { Kadar } \mathrm{NaCl} \\
\text { yang Tertahan }\end{array}$} \\
\hline & $\begin{array}{c}\text { Abu } \\
\text { Gosok }\end{array}$ & $\begin{array}{l}\text { Batang } \\
\text { Pisang }\end{array}$ & $\begin{array}{c}\text { Eceng } \\
\text { Gondok }\end{array}$ & & & & & \\
\hline 1 & 10 & 0 & 10 & 0,1 & 4 & 20 & 0,02 & 80,00 \\
\hline 2 & 0 & 10 & 10 & 0,1 & 6,6 & 20 & 0,033 & 67,00 \\
\hline 3 & 10 & 10 & 0 & 0,1 & 14,65 & 20 & 0,07325 & 26,75 \\
\hline
\end{tabular}

Tabel.3 Kadar $\mathrm{NaCl}$ yang tertahan pada adsorben menggunakan tiga (3) jenis adsorben

\begin{tabular}{ccccccccc}
\hline \multirow{2}{*}{ Perlakuan } & \multicolumn{2}{c}{ Komposisi Adsorben $($ gram $)$} & Kadar & Volume & Volume & Kadar & \% Kadar NaCl \\
\cline { 2 - 5 } & $\begin{array}{c}\text { Abu } \\
\text { Gosok }\end{array}$ & $\begin{array}{c}\text { Batang } \\
\text { Pisang }\end{array}$ & $\begin{array}{c}\text { Eceng } \\
\text { Gondok }\end{array}$ & $\begin{array}{c}\text { AgNO3 } \\
\text { AgNO3 }\end{array}$ & $\begin{array}{c}\text { NaCl } \\
\text { Nang Tertahan }\end{array}$ \\
\hline 1 & 10 & 5 & 5 & 0,1 & 2,95 & 20 & 0,01475 & 85,25 \\
2 & 5 & 10 & 5 & 0,1 & 3,4 & 20 & 0,017 & 83,00 \\
3 & 10 & 2 & 8 & 0,1 & 4,4 & 20 & 0,022 & 78,00 \\
4 & 5 & 5 & 10 & 0,1 & 4,5 & 20 & 0,0225 & 77,50 \\
5 & 4 & 6 & 10 & 0,1 & 4,75 & 20 & 0,02375 & 76,25 \\
6 & 10 & 4 & 6 & 0,1 & 4,85 & 20 & 0,02425 & 75,75 \\
7 & 10 & 6 & 4 & 0,1 & 5 & 20 & 0,025 & 75,00 \\
8 & 10 & 8 & 2 & 0,1 & 6,05 & 20 & 0,03025 & 69,75 \\
9 & 2 & 8 & 10 & 0,1 & 6,65 & 20 & 0,03325 & 66,75 \\
10 & 8 & 10 & 2 & 0,1 & 6,7 & 20 & 0,0335 & 66,50 \\
11 & 6 & 4 & 10 & 0,1 & 7 & 20 & 0,035 & 65,00 \\
12 & 6 & 10 & 4 & 0,1 & 8,45 & 20 & 0,04225 & 57,75 \\
\hline
\end{tabular}

Tabel.4 Kadar NaCl Sampel air laut (Pantai Gading Lombok)

\begin{tabular}{cccccccccc}
\hline \multirow{2}{*}{$\begin{array}{c}\text { Perla } \\
\text { kuan }\end{array}$} & \multicolumn{3}{c}{ Sebelum dilewatkan Adsorben } & \multicolumn{3}{c}{ Sebelum dilewatkan Adsorben } & \% Kadar \\
\cline { 2 - 7 } $\begin{array}{c}\text { Rata- } \\
\text { rata }\end{array}$ & AgNO3 & Volume & Volume & Kadar & Kadar & Volume & Volume & Kadar & NaCl yang \\
& 0,1 & 2,75 & 20 & 0,01375 & 0,1 & 1,2 & 20 & 0,006 & 56,36 \\
\hline
\end{tabular}

DAFTAR PUSTAKA

[1] Ismillayli, N., Hermanto, D., Kamali, S. R., \& Fahrurazi, F. (2016). DESALINASI BERBASIS
TENAGA SURYA DI KECAMATAN BAYAN LOMBOK UTARA. Jurnal Pijar Mipa, 11(2). 
[2] Statistik, B. P. (2011). Statistik pertanian. Badan Pusat Statistik, Jakarta.

[3] Cordeiro, N., Belgacem, M. N., Torres, I. C., \& Moura, J. C. V. P. (2004). Chemical composition and pulping of banana pseudostems. Industrial Crops and Products, 19(2), 147-154.

[4] Li, K., Fu, S., Zhan, H., Zhan, Y., \& Lucia, L. (2010). Analysis of the chemical composition and morphological structure of banana pseudostem. BioResources, 5(2), 576-585.

[5] Hasanah, A. N., Rizkiana, F., \& Rahayu, D. (2012). Banana Peels and Stem (Musa X paradisiaca Linn.) as Biosorbent of Copper in Textile Industry Wastewater. Research Journal of Pharmaceutical Biological and Chemical Sciences, 3(3), 1171.

[6] Widihati, I. A. G., Suastuti, N. G. A. M. D. A., \& Nirmalasari, M. Y. (2012). Studi kinetika adsorpsi larutan ion logam kromium (Cr) menggunakan arang batang pisang (Musa paradisiaca). Jurnal Kimia, 6(1), 8-16.

[7] Becker, H., Matos, R. F., Souza, J. A. D., Lima, D. D. A., Souza, F. T. C. D., \& Longhinotti, E. (2013). Pseudo-stem banana fibers: characterization and chromium removal. Orbital: The Electronic Journal of Chemistry, 5(3), 164170.

[8] Hidayah, N., Deviyani, E., \& Wicakso, D. R. (2012). adsorpsi logam besi (Fe) sungai barito menggunakan adsorben dari batang pisang. Konversi, 1(1), 19-26.

[9] Megawati, N. M. S., Putra, A. A. B., \& Sibarani, J. (2013). Pemanfaatan Arang Batang Pisang (Musa Paradisiacal) Untuk Menurunkan Kesadahan Air. Jurnal Kimia, 7.

[10] Ikhwan, Z. (2017). Efektifitas Bio Sorben Keladi, Eceng Gondok dan Batang Pisang pada Kandungan Fosfat Limbah Laundry. Jurnal Kesehatan Masyarakat Andalas, 10(1), 45-51.

[11] Bhattacharya, A., \& Kumar, P. (2010). Water hyacinth as a potential biofuelcrop. Electron $\mathbf{J}$ Environ Agric Food Chem, 9(1), 112-122.

[12] Gunnarsson, C. C., \& Petersen, C. M. (2007). Water hyacinths as a resource in agriculture and energy production: A literature review. Waste Management, 27(1), 117-129.

[13] Asip, F., Afrizal, R., \& Rosa, S. S. (2008). Pembuatan Oil Adsorbant dari Eceng Gondok. Jurnal Teknik Kimia, 15(4).

[14]Chen, X., Chen, X., Wan, X., Weng, B., \& Huang, Q. (2010). Water hyacinth (Eichhornia crassipes) waste as an adsorbent for phosphorus removal from swine wastewater. Bioresource Technology, 101(23), 9025-9030.

[15] Herawati, N. (2013). Pemanfaatan Eceng Gondok Sebagai Zat Penyerap Warna Pada Industri Tekstil Sebagai Upaya Mengurangi Pencemaran Air. Berkala Teknik, 3(2), 554-562.

[16] Kanawade, S. M., \& Gaikwad, R. W. (2011). Removal of methylene blue from effluent by usingactivated carbon and water hyacinth as adsorbent. International Journal of Chemical Engineering and Applications, 2(5), 317.

[17] Buasri, A., Chaiyut, N., Tapang, K., Jaroensin, S., \& Panphrom, S. (2012). Biosorption of heavy metals from aqueous solutions using water hyacinth as a low cost biosorbent. Civil Environ Res, 2(2), 17-25.

[18] Tangio, J. S. (2013). Adsorpsi logam timbal (Pb) dengan menggunakan biomassa enceng gondok (Eichhorniacrassipes). Jurnal Entropi, 8(01).

[19] Muchtar, Z. (2013). Pengaruh Enceng Gondok Dan Kapur Terhadap Unit Pengolahan Air Gambut. Pilar, 9(2).

[20] Yustinah, Y., Rahayu, R. A. N., \& Cardosh, S. R. (2014). Pengaruh Massa Bioadsorben dari Enceng Gondok pada Proses Pemurnian Minyak Sawit Mentah (CPO). Prosiding Semnastek, 1(1).

[21] Tudjuka, M. D., Walanda, D. K., \& Hamzah, B. Arang Eceng Gondok (Eichornia crassipes) sebagai Adsorben Fenol pada Limbah PLTU Palu. Jurnal Akademika Kimia, 6(2), 119-124.

[22] Fernández-Jiménez, A., \& Palomo, A. (2005). Composition and microstructure of alkali activated fly ash binder: Effect of the activator. Cement and concrete research, 35(10), 1984-1992.

[23] Setyaningtyas, T., \& Sulaeman, U. (2007). Pengaruh pH Larutan Dan Ukuran Partikel Abu Sekam Padi Terhadap Penurunan Kadar Congo Red. Molekul, 2(1), 7-12.

[24] Alma'arif, A. L., Wijaya, A., \& Murwono, D. (2012). Penghilangan racun asam sianida (HCN) dalam umbi gadung dengan menggunakan bahan penyerap abu. Jurnal Teknologi Kimia dan Industri, 1(1), 14-20.

[25] Yusuf, M. A. (2013). Adsorpsi Ion Cr (VI) oleh Arang Aktif Sekam Padi (Adsorption Ions Of $\mathrm{Cr}$ (VI) By Active Rice Husk Charcoal). Unesa Journal of Chemistry, 2(1).

[26] Nurhasni, N., Hendrawati, H., \& Saniyyah, N. (2014). Sekam Padi untuk Menyerap Ion Logam Tembaga dan Timbal dalam Air Limbah. Jurnal Kimia Valensi, 4(1). 
J. Pijar MIPA, Vol. 15 No.2, Maret 2020: 165-170

DOI: $10.29303 / j p m . v 15 i 2.1625$

[27] Hakim, L. N., Syarifudin, A., \& Hamzani, S. (2016). Efektifitas Abu Sekam Padi Dan Poly Aluminium Chloride Dalam Menurunkan Zat Warna Limbah Cair Industri Sasirangan. Jurnal Kesehatan Lingkungan: Jurnal dan Aplikasi Teknik Kesehatan Lingkungan, 13(2), 346-354.

[28] Wardalia, W. (2016). Karakterisasi Pembuatan Adsorben Dari Sekam Padi Sebagai Pengadsorp Logam Timbal Pada Limbah Cair. Jurnal Integrasi Proses, 6(2).
ISSN 1907-1744 (Cetak)

ISSN 2460-1500 (Online)

[29] Suryati, T. (2011). Eliminasi logam berat kadmium dalam air limbah menggunakan tanaman air. Jurnal Teknologi Lingkungan, 4(3).

[30] Ismillayli, N., Mardiana, L., Kurnianingsih, R. Hermanto, D., \& Fahrurazi, F. (2017). Teknologi Pengelolaan Air Siap Minum Di Desa Jago Kabupaten Lombok Tengah. Jurnal Pijar Mipa, 12(2), 102-106. 